\title{
Aa. Vv., «Fifteenth-Century Studies», 32
}

\section{Maria Colombo Timelli}

\section{(2) OpenEdition}

\section{Journals}

\section{Édition électronique}

URL : http://journals.openedition.org/studifrancesi/8836

DOI : 10.4000/studifrancesi.8836

ISSN : 2427-5856

\section{Éditeur}

Rosenberg \& Sellier

\section{Édition imprimée}

Date de publication : 1 octobre 2008

Pagination : 434-435

ISSN : 0039-2944

\section{Référence électronique}

Maria Colombo Timelli, «Aa. Vv., «Fifteenth-Century Studies», 32 », Studi Francesi [En ligne], 155 (LII ]

II) | 2008, mis en ligne le 30 novembre 2015, consulté le 13 janvier 2021. URL : http://

journals.openedition.org/studifrancesi/8836 ; DOI : https://doi.org/10.4000/studifrancesi.8836

Ce document a été généré automatiquement le 13 janvier 2021.

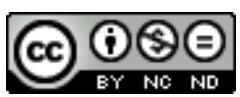

Studi Francesi è distribuita con Licenza Creative Commons Attribuzione - Non commerciale - Non opere derivate 4.0 Internazionale. 


\title{
Aa. Vv., «Fifteenth-Century Studies», 32
}

\author{
Maria Colombo Timelli
}

\section{RÉFÉRENCE}

«Fifteenth-Century Studies», 32, 2006.

1 Ce numéro de «FCS» est dédié à Edelgard E. Du Bruck, fondatrice et animatrice de la revue. Comme d'habitude, nous signalons les articles concernant la littérature française $\mathrm{du} \mathrm{XV}^{\mathrm{e}}$ siècle.

Karen CASÉBIER, Re-writing Lucretia: Christine de Pizan's Response to Boccaccio's “De Mulieribus Claris", pp. 35-52.

3 L'histoire de Lucrèce, que Christine tire du De Mulieribus Claris, est adaptée dans la Cité des Dames à une nouvelle vision de la femme et de la société: l'héroïne romaine violée par Tarquinius devient le symbole de la vertu naturelle des femmes, et la violence qu'elle subit ne dépend que du vice des hommes.

olga Anna DUHL, Vernacular Translation and the Sins of the Tongue: From Brant's "Stultifera Navis" (1494) to Droyn's “La Nef des folles” (c. 1498), pp. 53-67.

La Nef des folles, traduction-adaptation en français de la Stultifera Navis, jouit d'un remarquable succès au XVI ${ }^{\mathrm{e}}$ siècle (cinq éditions entre 1498 et 1583). S'adressant tout spécialement à un public de lectrices, son auteur, Jehan Droyn, réécrit sa source en l'amplifiant: O.A.D. souligne en particulier le traitement réservé aux péchés de la langue et au 'multiloquium', considéré comme typique des femmes, mais auquel Droyn lui-même n'a pas su se soustraire.

christiane RAYNAUD, Portrait d'une carrière extraordinaire: Bertrand Du Guesclin, chef de guerre modèle, dans la "Chronique anonyme dite des Cordeliers" (c. 1432), pp. 100-117.

7 L'auteur de cette chronique bourguignonne consacre à Bertrand Du Guesclin un portrait qui occupe quelque 55 feuillets: aspect physique, qualités morales et 
psychologiques, faits d'armes, quelques anecdotes, étapes de sa carrière. L'originalité de cette biographie réside d'une part dans son étendue, d'autre part dans la concision du récit et dans la sobriété du style.

8 Barbara N. SARGENT-BAUR, False Starts and Ambiguous Clues in François Villon's "Testament" (1461), pp. 133-149.

9 L'A. relit le Testament pour y déceler les traces du poète et du rapport qu'il instaure avec ses lecteurs. Elle relève ainsi que la progression du poème n'est ni linéaire ni logique, et que Villon crée, du début à la fin du texte, des attentes qui ne seront jamais satisfaites, et semble promettre une rencontre qui ne se réalisera finalement pas.

10 Steven Millen TAYLOR, Down to Earth and Up to Heaven: The Nine Muses in Martin Le Franc's "Le Champion des Dames", pp. 164-175.

11 Martin Le Franc introduit les Muses dans le Livre IV de son Champion des Dames (huitains 423-462). Il en fait des personnages humains, et par conséquent des modèles proposés à l'imitation des femmes. Dans sa défense, Franc Vouloir suggère que celles-ci pourraient développer leurs qualités et améliorer le contexte social où elles vivent. 